\title{
EDUCAÇ̃̃O CONTINUADA EM CIÊNCIAS E MATEMÁTICA NO CECIRS ENTRE OS ANOS DE 1985 E 2000: UM ESTUDO DAS CONCEPC̣ÕES EDUCACIONAIS DO PROFESSOR VICENTE HILLEBRAND
}

\author{
Glauce Agnes Balestrin* \\ Regina Maria Rabello Borges **
}

RESUMO: O presente artigo tem por objetivo reconstruir a trajetória de vida profissional do professor Vicente Hillebrand, responsável pela educação matemática no Centro de Ciências do Rio Grande do Sul (CECIRS), a fim de compreender como foi o trabalho desenvolvido por ele na educação continuada de professores e, ainda, de que forma as interações que ele estabeleceu com seus colegas no CECIRS influenciaram suas concepções educacionais. Evidenciou-se que essas interações proporcionaram a ele um crescimento diferenciado, uma vez que todos os integrantes do centro podiam colaborar para modificar as concepções de seus colegas por meio de um esforço coletivo e contínuo. Verificou-se, também, que repensar suas concepções educacionais permitiu ao professor Vicente Hillebrand contribuir de forma valiosa para a atuação pedagógica dos professores que participaram dos grupos de estudos, o que se refletia diretamente na qualidade do ensino nas escolas.

Palavras-chave: Centro de Ciências do Rio Grande do Sul. Educação continuada em ciências e matemática. Concepções educacionais.

EDUCACIÓN CONTINUADA EN CIENCIAS Y MATEMATICAS EN EL CECIRS ENTRE LOS AÑOS 1985 Y 2000: UN ESTUDIO DE LAS CONCEPCIONES EDUCACIONALES DEL PROFESOR VICENTE HILLEBRAND

RESUMEN: Este artículo tiene por objetivo reconstruir la trayectoria de vida profesional del profesor Vicente Hillebrand, responsable por la educación matemática del Centro de Ciencias del Rio Grande do Sul (CECIRS), con fines de comprender como fue el trabajo desarrollado por él en la educación continuada de profesores y, además, de qué forma las interacciones que él estableció con sus compañeros en el CECIRS influenciaron sus concepciones educacionales. Se evidenció que esas interacciones proporcionaron a él un crecimiento diferenciado, una vez que todos los integrantes del centro podían colaborar para cambiar las concepciones de sus compañeros por medio de un esfuerzo colectivo y continuo. Se verificó también que repensar sus concepciones educacionales permitió al profesor Vicente Hillebrand contribuir de forma valerosa para la actuación pedagógica de los profesores que participaron de los grupos de estudios directamente en la calidad de enseñanza en las escuelas.

Palabras clave: Centro de Ciencias do Rio Grande do Sul. Educación continuada en ciencias y matemáticas. Concepciones educacionales

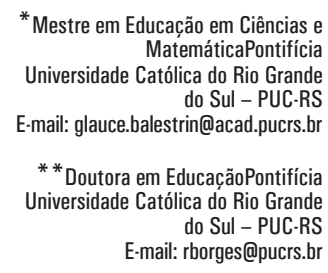

* Mestre em Educação em Ciências e MatemáticaPontifícia Universidade Católica do Rio Grande do Sul - PUC-RS E-mail: glauce.balestrin@acad.pucrs.br

* * Doutora em EducaçãoPontifícia Universidade Católica do Rio Grande do Sul - PUC-RS E-mail: rborges@pucrs.br 


\section{CONTINUED EDUCATION IN SCIENCE AND MATHEMATICS AT THE CECIRS BETWEEN THE YEARS 1985 AND 2000: A STUDY OF THE EDUCATIONAL CONCEPTIONS VICENTE HILLEBRAND TEACHER}

ABSTRACT: This article presents the historical reconstruction of the continued formation of teachers highlighting Professor Vincente Hillebrand's job, responsible for Mathematics Education at the Centre, in order to understand how was his work with the teachers continued formation and how the connections he stablished with other teachers influenced his educational conceptions at that time. It was evident that these interactions have provided him a different type of growth, since all the Centre's members could work together to change the views of their colleagues through a collective and continuous effort. It was also verified that rethinking their educational conceptions allowed the teacher Vicente Hillebrand to make a valuable contribution in the educational performance of teachers who participated in the study group, which was directly reflected in the quality of education in schools.

Key Words: Rio Grande do Sul Centre Science. Mathematics. Continued Education. Educational Concepts. 


\section{INTRODUCุÃO}

A pesquisa apresentada neste artigo está relacionada ao projeto interinstitucional denominado "Ciência, História, Educação e Cultura: dos Centros de Treinamento de Professores de Ciências aos atuais Centros e Museus Interativos" (PUCRS, UFPE, UFBA), vinculado ao Programa Pró-Cultura - uma parceria da Coordenação de Aperfeiçoamento de Pessoal de Nível Superior (Capes) com o Ministério da Cultura (MinC).

Durante a década de 1960, o Ministério da Educação e Cultura (MEC) reconheceu a situação desfavorável do ensino brasileiro frente às novas metas mundiais para a educação propostas pelos organismos internacionais - Unesco, OEA - e, diante da necessidade alegada de mudanças que incorporassem conhecimentos e experiências em áreas estratégicas nos currículos escolares e nos programas de ensino, criou seis Centros de Ciências, distribuídos em diferentes Estados brasileiros. São eles: CECISP - Centro de Ciências de São Paulo; CECIBA - Centro de Ciências da Bahia; CECIRS - Centro de Treinamento para Professores de Ciências do Rio Grande do Sul; CECIGUA - Centro de Treinamento para Professores de Ciências da Guanabara, no Rio de Janeiro, depois denominado CECIERJ, quando foi criado o Estado do Rio de Janeiro; CECINE - Centro de Ensino de Ciências do Nordeste; e CECIMIG - Centro de Treinamento para Professores de Ciências de Minas Gerais. Entre os objetivos deste projeto está o de

reconstruir a história desses centros, a partir da busca de documentos e de entrevistas com pessoas que deles tenham participado, com ênfase no papel que desempenharam na popularização das ciências e no desenvolvimento da cultura científica e tecnológica no Brasil. (BORGES; SILVA; DIAS, 2009)

Nesse contexto, o presente artigo apresenta um estudo com ênfase no ensino de matemática promovido pelo CECIRS. Especificamente, buscou-se identificar como foi o trabalho desenvolvido pelo professor Vicente Hillebrand ${ }^{1}$, responsável pela matemática no Centro de Ciências do Rio Grande do Sul de 1985 a 2000, na educação continuada de professores de matemática, e, ainda, compreender como as interações que ele estabeleceu com outros professores naquela época influenciaram suas concepções educacionais.

Ao longo de toda a sua história, o CECIRS buscou a melhoria da qualidade do ensino de ciências, adotando estratégias que consistiam, inicialmente, em ações sobre professores, em todas as redes de ensino. Esse ideal do centro era impulsionado pela vontade de mudar a realidade do ensino de ciências a partir da qualificação dos professores. Por esse mesmo motivo, com o passar do tempo, os professores de matemática passaram a ser alvo das iniciativas do CECIRS. Mantendo presente em suas ações o objetivo de "contribuir para a melhoria da qualidade do ensino das disciplinas científicas no ensino fundamental e médio" (CECIRS, 1999, p. 4), o CECIRS, em consonância com as partes envolvidas, comprometia-se a capacitar e 
aperfeiçoar professores de ciências e matemática e, para tanto, empregava algumas linhas de ação. Acerca destas, salienta-se que

graças a importantes convênios com a CAPES, através do PADCT [Programa de Apoio ao Desenvolvimento Científico e Tecnológico] e do SPEC [Subprograma Educação para a Ciência], a equipe do centro conseguiu desenvolver projetos que beneficiaram diretamente alunos e professores da rede de ensino do RS” (CECIRS, 1999, p. 6).

Destacaram-se entre as ações a atuação com professores envolvendo, entre outras atividades, palestras, cursos, grupos de estudo e assessorias; a produção de materiais de ensino, como livros e revistas; atividades extraclasses, incluindo as Feiras de Ciências, que contavam com a participação e o envolvimento de todas as Delegacias de Educação (DE-RS), de alunos, professores e da coordenação das escolas. Outros destaques entre as linhas de ação propostas pelo CECIRS referem-se às pesquisas relacionadas a metodologias de ensino e à criação de materiais para laboratório de ciências e matemática, e à organização, à coordenação e à participação em fóruns, debates, mostras e outros eventos (CECIRS, 1999, p. 5).

No início da década de 1980, o trabalho desenvolvido no centro passou a ser concebido em conjunto com as Delegacias de Educação (DE-RS), por meio dos supervisores de ciências e matemática, e a estratégia usada se transformou em ações com os professores. Nesse mesmo período, mais precisamente em 1985, o professor Vicente Hillebrand passou a integrar a equipe do CECIRS, assumindo os trabalhos inerentes à disciplina de matemática, que envolviam palestras, cursos, grupos de estudo e assessorias.

As atividades desenvolvidas pelo CECIRS ao longo de sua existência apontavam, essencialmente, para a importância de o professor refletir constantemente sobre a sua prática pedagógica. Justificava-se, dessa forma, a necessidade de o professor reavaliar sua prática, levando em conta ainda os problemas de origem pedagógica que afetavam os cursos de licenciatura, nos quais, de maneira geral, as disciplinas eram descontextualizadas, com pouca integração entre si, comprometendo, assim, a formação inicial de professores de ciências e matemática. Nesses cursos, podia ser identificado um modelo formativo com foco na aquisição de conhecimentos, que devia ser superado, conforme a avaliação dos integrantes do centro.

As ideias presentes nas ações do CECIRS a partir dos anos de 1980 podem ser facilmente relacionadas a alguns aspectos que caracterizam a pedagogia libertadora de Paulo Freire. Contudo, alguns aspectos próprios da pedagogia tecnicista ainda influenciavam as ações do grupo, como, por exemplo, a ideia de que cabia à educação "proporcionar um eficiente treinamento para a execução das múltiplas tarefas demandadas continuamente pelo sistema social” (SAVIANI, 2008, p. 383) de um mundo em permanente mudança.

Por sua vez, entre os projetos propostos pelo CECIRS na década de 1990, houve ênfase nos grupos de estudo. O professor Vicente Hillebrand atuou como coordenador no Grupo de Estudo de Matemática, que envolvia professores do Sistema 
Estadual de Educação e era realizado em oito encontros semanais de três horas cada. O trabalho era desenvolvido com foco na necessidade de o professor buscar aperfeiçoar-se continuamente, avaliando e replanejando sua prática pedagógica, e também no reconhecimento da importância de dinamizar as aulas, tornando o aluno sujeito participativo do processo de aprendizagem (CECIRS, 1999).

Em 1999, no entanto, a impressão predominante foi de perplexidade, devido à desarticulação do CECIRS, tendo permanecido apenas a sigla no organograma da diretoria pedagógica da Secretaria de Educação e uma telefonista de plantão para receber as ligações no que restou da antiga sede. Houve suspensão de todas as linhas de ação: atuação com professores, Feiras de Ciências, pesquisas educacionais e publicações. Foram cortados os vínculos entre o CECIRS e outras instituições afins, em âmbito nacional e internacional. Ocorreu a desmontagem dos laboratórios da sede, com cedência do espaço físico e dos recursos materiais. A equipe, impotente para reverter esse quadro, reunia-se em busca de alternativas para que o CECIRS, mesmo passando por transformações, não perdesse sua identidade. Mas não eram transformações que estavam sendo cogitadas; os profissionais que ali trabalhavam começaram a ser convidados a atuar em outros setores, o que foi destacado em documentos de circulação interna da Secretaria de Educação do Estado do Rio Grande do Sul como uma das estratégias para a extinção do CECIRS. Ao longo daquele ano, houve uma extinção lenta, gradual e dissimulada, negada oficialmente, mas que terminou acontecendo de fato em dezembro, no início das férias escolares.

O CECIRS foi se transformando ao longo do tempo, à medida que conciliava conflitos e discussões com estabilidade e continuidade. Mas por que foi desativado? Essa pergunta permanece sem resposta oficial. Entretanto, assim como a contextualização das concepções assumidas pelo CECIRS em diversos períodos históricos é importante, o resgate de sua história e a conscientização sobre o momento atual são fundamentais.

Para reconhecer as concepções educacionais presentes nas ações do CECIRS, e que envolviam o trabalho do professor Vicente Hillebrand no centro, esta pesquisa encontra-se apoiada em diversos estudos sobre correntes pedagógicas que têm marcado a educação no Brasil (TEIXEIRA, 2003; GADOTTI, 1999; LIBÂNEO, 2001; SAVIANI, 2005, 2008), de modo geral, classificadas como: (1) tradicional, caracterizada por dar prioridade à teoria sobre a prática; (2) escolanovista, que corresponde a um ensino que parte das necessidades particulares do educando, consideradas importantes para sua adaptação ao meio, segundo a qual o centro é o aluno como sujeito do cohecimento; (3) tecnicista, na qual a educação é vista como um recurso tecnológico por excelência, capaz de treinar os alunos a fim de ajustar seus comportamentos às metas econômicas, sociais e políticas impostas pela sociedade tecnológica; e (4) progressista, que manifestou-se em três importantes vertentes, todas com ponto forte na dimensão político-social, são elas: a pedagogia libertadora, teorizada por Paulo Freire; a pedagogia libertária, em que a autogestão é assumida como conteúdo e método; e a pedagogia crítico-social do conteúdo, 
que dá ênfase ao confronto entre o conteúdo e a realidade social. Sem aprofundar essa teorização, é apresentada, a seguir, a metodologia adotada para a análise e a interpretação desta pesquisa.

\section{Metodologia de pesquisa}

A abordagem da pesquisa aqui apresentada foi qualitativa (BOGDAN; BIKLEN, 1994; LÜDKE; ANDRÉ, 2001), pois se caracterizou por buscar a compreensão sem generalizar. "Os resultados escritos da investigação contêm citações feitas com base nos dados para ilustrar e substanciar a apresentação" (BOGDAN; BIKLEN, 1994, p. 48), que inclui, por exemplo, transcrições de entrevistas, como é o caso da presente pesquisa.

Trata-se de um estudo de caso único, envolvendo a trajetória profissional de um professor que trabalhou a educação matemática no Centro de Ciências do Rio Grande do Sul (CECIRS) no período de 1985 a 2000. Yin (2010) considera que "o estudo de caso deve ser significativo", argumentando que "um estudo de caso único pode ter sido escolhido por ser um caso revelador” (YIN, 2010, p. 217) que reflita alguma situação não estudada.

O instrumento de coleta de dados empregado nesta pesquisa foi a entrevista semiestruturada - além de análise dos seguintes trabalhos de autoria do professor Vicente Hillebrand: Hillebrand (1985a; 1985b; 1985c; 1985d; 1985e; 1986; 1988; 1996; 1998; 2000; 2011) e Hillebrand e Zaro (1999). Para Lüdke e André (2001, p. 34), "é importante atentar para o caráter de interação que permeia a entrevista", pois ela "permite correções, esclarecimentos e adaptações que a tornam sobremaneira eficaz na obtenção das informações desejadas”.

Para analisar as informações obtidas, adotou-se a metodologia de Análise Textual Discursiva proposta por Moraes e Galiazzi (2011), "compreendida como um processo auto-organizado de construção de compreensão em que novos entendimentos emergem" (MORAES; GALIAZZI, 2011, p. 12) à medida que acontece um aprofundamento rigoroso das informações contidas nos materiais de análise fruto de entrevistas.

\section{Resultados obtidos}

Ao se analisar a entrevista e reconstituir a história desse espaço de formação continuada de professores de ciências e matemática, tornou-se possível compreender que o espírito que orientava esses cursos "era o de melhorar o ensino de matemática, por meio de atividades de redescoberta, no sentido de instrumentalizar o professor para desenvolver aulas em que o aluno descobrisse relações matemáticas a partir de sua prática” (HILLEBRAND, 2011, p. 8).

Tendo em vista o caráter coletivo de trabalho, e considerando-se a necessidade de o professor avaliar, replanejar e aperfeiçoar seu trabalho, a equipe do CECIRS passou a apostar, dentre outros projetos, em grupos de estudo que oportunizassem aos professores leituras, discussões, troca de experiências e uma constante reflexão sobre a própria docência, como uma necessidade de qualquer 
profissional. Nessa perspectiva, foi possível observar no relato do professor Vicente seu entusiasmo e sua satisfação ao relembrar seu trabalho com grupos de estudo. Ficou evidente que, para ele, os grupos de estudo constituem-se ambientes privilegiados e também eficientes, em que o compartilhar experiências e a constante reflexão sobre a própria prática possibilitam atingir de forma significativa os participantes, promovendo de fato uma formação continuada. Assim, nas palavras do professor Vicente,

[...] a oportunidade de eles refletirem sobre a sua prática, de compartilhar experiências era muito rica. Eles compartilhavam de fato experiências, vivências na sua escola. Um professor perguntava para o outro "como é que você faz isso?", "eu faço assim”, "ah! Que legal. Interessante!", "não tinha pensado nisso". Isto é muito enriquecedor. [...] E se trabalhava, se estudava... isso era o bom do trabalho, o estudo que os professores queriam fazer; eles vinham porque queriam se aperfeiçoar, aprimorar as próprias condições de trabalho. A nossa atuação com eles era uma ajuda, uma possibilidade de compartilharem ideias e atividades. (Dados de entrevista realizada para esta pesquisa)

Freire (1994) fundamenta e reforça esse modo de pensar e agir, pois, "[...] na formação permanente dos professores, o momento fundamental é o da reflexão crítica sobre a prática. É pensando criticamente a prática de hoje ou de ontem que se pode melhorar a próxima prática" (FREIRE, 1994 p. 22).

O reconhecimento dessa valiosa contribuição dos grupos de estudo na atuação pedagógica dos professores pode ser naturalmente notado em muitas avaliações desses cursos reunidas e encadernadas pelo professor Vicente no formato de um livro, intitulado Avaliações de Cursos de Matemática (HILLEBRAND, 2011). Essas avaliações apresentam depoimentos de professores que participaram dos cursos realizados pelo professor Vicente em várias cidades do Rio Grande do Sul, em Santa Catarina, no Paraná e até em Sergipe. De maneira geral, essa compilação de documentos traduz a satisfação dos professores com relação aos ensinamentos do professor Vicente Hillebrand nos cursos. Um dos participantes de um curso de 1987 em Aracajú ressalta que "a habilidade do professor junto à sua sede de desenvolver uma nova visão na transmissão dos conceitos matemáticos foram tais que as dificuldades ou necessidades que pudessem aparecer caíram por terra, sobrepujadas" (Depoimento de professor. In: HILLEBRAND, 2011, p. 27 ).

Merece destaque aqui a avaliação de outro professor de Aracajú, em 1987:

Durante essa semana tivemos a oportunidade de viver o ensino da matemática de uma forma bastante concreta, forma esta que foge totalmente ao tradicional ensino passado em nossas escolas. [...] A minha maior preocupação fica por conta do que acontecerá após este curso, que nos traz uma nova metodologia, que nos mostra o ensino da matemática totalmente contrário ao convencional, ou seja, que desperta no aluno a criatividade, a experimentação, o questionamento, para que possa chegar a conceitos, e que tudo isso poderá perder-se na insegurança que nós, educadores, temos e diria também na coragem que não temos para experimentar o novo. (Depoimento de professor. In: HILLEBRAND, 2011, p. 24) 
Esse professor mostra-se bastante empolgado com as novas possibilidades em termos metodológicos que o curso lhe oportunizou. É possível notar que a abordagem predominantemente associada à sua prática refere-se à abordagem tradicional de ensino, enquanto o curso ministrado pelo professor Vicente Hillebrand estaria ancorado em uma metodologia que buscaria despertar no aluno a criatividade, a experimentação, o questionamento etc., partindo de atividades concretas. Nota-se que essa inovação proposta pelo professor Vicente não é uma tarefa simples para alguns professores que, "presos" a uma metodologia de ensino tradicional, demonstram medo e insegurança para liberar-se do convencional e buscar novas alternativas.

Outro aspecto percebido no relato do professor Vicente, e que merece ser destacado, remete ao fato de que muitos dos professores vinham para os cursos ou grupos de estudo com sérias dificuldades de conteúdo e também instrumentais. A respeito dessas dificuldades, o professor Vicente Hillebrand destaca: "Percebia algumas dificuldades bem grandes; de desconhecimento de aspectos de matemática, de temas básicos de matemática, de não saber como se faz isso". O reconhecimento pelos próprios professores das suas dificuldades também acontecia, primeiramente, mediante uma reflexão individual da sua prática. O importante era que eles assumiam a necessidade de aprimorar seus conhecimentos pedagógicos, tinham consciência da importância de buscar uma formação continuada, e era essa vontade de crescer como profissionais que os levava para os cursos e os grupos de estudo. Nesse sentido, o professor Vicente Hillebrand relembra:

Muitos, para não dizer a maioria, se queixavam de não saber como dar aula, ou como dar uma aula mais interessante, e isto os trazia para os cursos. Era comum eles se queixarem de não saberem como fazer melhor, cheios de boa vontade. [...] Gostariam de fazer, e alguns diziam isso abertamente: "eu não sei como fazer"! "Eu não sei como se faz isto". E isso os trazia para os cursos, para os grupos de estudo. (Dados de entrevista realizada para esta pesquisa)

O envolvimento intenso do professor Vicente Hillebrand com os grupos de estudo foi tão valioso para ele que logo se tornou foco da sua dissertação de mestrado (HILLEBRAND, 1996) e também da sua tese de doutorado (HILLEBRAND, 2000). No decorrer da entrevista, o professor Vicente recordou uma viagem que fez juntamente com o professor Roque Moraes, também membro do CECIRS naquela época, quando o convidou para ser seu orientador no mestrado. Na ocasião, ele estava formulando sua questão de pesquisa diante de alguns questionamentos embasados na sua experiência com grupos de estudo e outros que podem ter surgido também durante a conversa com o professor Roque. O desafio estava em compreender o que um grupo de estudos faz, o que ele traz para o professor e o que o fato de participar de um grupo de estudos muda na vida dos docentes. O professor Vicente acrescenta:

Eu estava pensando sobre isso: que importância tem esse grupo para esses professores. Muda alguma coisa na atuação deles? Aí veio o tema e o título: Contribuições de um grupo de estudos na atuação pedagógica de professores de matemática. Esse foi o foco da dissertação que eu desenvolvi com um grupo de Gravataí. (Dados de entrevista realizada para esta pesquisa) 
Em resposta às questões propostas em sua pesquisa, surgiram argumentos que apontavam, principalmente, para a necessidade que os professores sentiam de aprender novas metodologias para trabalhar com a matemática de forma prática, além do reconhecimento de que isso se torna ainda mais enriquecedor quando acontece compartilhando experiências.

Nos encontros que se seguiram com o grupo de estudos foco da dissertação de Hillebrand, os professores responderam ao questionamento: "Como eu me sinto como professor de matemática?". Nesse contexto, muitos lamentaram a angústia ou a frustração que sentiam diante de alunos desmotivados com a aprendizagem em matemática e acreditavam que esse desinteresse acontecia em decorrência de alguns fatores como, por exemplo, a preferência das crianças por atividades mais envolventes, como andar de bicicleta, um programa de televisão ou um jogo qualquer, em vez de estarem "presos" a uma aula que se resumia em quadro-negro, giz, mesas e cadeiras. Além disso, muitos lamentaram dizendo que seus alunos não eram ensinados a pensar, mas, sim, obrigados a responder de forma a satisfazer os professores. Em contrapartida, os professores sentiam a necessidade de mudar essa realidade, de envolver mais seu aluno no processo de aprendizagem e, por isso, procuravam participar dos cursos ministrados pelo professor Vicente, que proporcionava a eles a oportunidade de construírem metodologias diferenciadas, partindo de atividades concretas e relacionando a teoria com a realidade do aluno. Entre os depoimentos dos professores - anexos à dissertação de mestrado do professor Vicente -, uma das professoras ressalta: "Hoje me sinto bastante motivada, pois acho que, com estes encontros, vamos abrir novos caminhos, chegar mais perto de nossos alunos, através de uma matemática mais prática, com mais motivação para nossas crianças" (Depoimento de professor. In: HILLEBRAND, 1996, p. 155).

Em outro momento da Secretaria de Educação, aconteceram as Jornadas Pedagógicas, que ocorriam em alguns lugares aos sábados (Ilha dos Marinheiros, Ilha das Flores e Ilha da Pintada). Tratava-se de eventos que reuniam professores da área de ciências com o intuito de oportunizar-lhes momentos de reflexão sobre a própria prática e também de desenvolverem um planejamento conjunto, possibilitando avaliarem os pontos positivos e os negativos do ano letivo e, por meio dessa avaliação, definirem mudanças significativas para o ensino e a aprendizagem dos alunos. O professor Vicente recorda: "Reuniam-se em uma escola, geralmente era na Ilha dos Marinheiros, e fazíamos atividades diversas com o chamado ' $\mathrm{Ma}$ terial Dourado', aquele para ensinar matemática, o sistema de numeração e outras atividades" (Dados de entrevista realizada para esta pesquisa).

O "Material Dourado" foi criado e idealizado pela médica e educadora italiana Maria Montessori. O trabalho que ela desenvolveu na educação era direcionado, inicialmente, para crianças com deficiências. Montessori observou que elas aprendiam mais com atividades que exigiam uma ação concreta, em vez de apenas a ação de pensar, e concluiu que métodos semelhantes poderiam ser aplicados também com crianças normais. Com base nas regras do sistema de nu- 
meração, esse material auxilia, principalmente, a aprendizagem das quatro operações matemáticas fundamentais: adição, subtração, multiplicação e divisão. Ainda que elaborado especialmente para o trabalho com a aritmética, o "Material Dourado" seguiu os mesmos princípios montessorianos da educação sensorial, de desenvolver na criança a independência, a confiança, a ordem e a coordenação, proporcionando experiências concretas que a conduzem a uma abstração cada vez maior do conhecimento. Além disso, a aprendizagem com esse material permite que a criança consiga, por si mesma, identificar possíveis erros que comete ao realizar uma determinada ação (SILVA; ARAUJO, 2012).

Diante dessas observações, é possível afirmar que, diferente do ensino tradicional, embasado na exposição verbal e na repetição de exercícios, fórmulas e conceitos, o professor Vicente optava por materiais que permitiam ao aluno compreender relações numéricas abstratas e desenvolver o raciocínio partindo de ações concretas. Foi no contexto do trabalho realizado com esse grupo de professores que participavam das Jornadas Pedagógicas que o professor Vicente deu origem à sua tese de doutorado.

Além desse trabalho realizado pelo professor Vicente com grupos de estudo, a entrevista permitiu identificar de que forma as interações que o professor Vicente manteve com outros professores naquela época influenciaram suas concepções educacionais, diante da complexidade das relações que se estabeleceram ao compartilhar experiências com os demais docentes, fossem eles participantes do CECIRS ou não, bem como em relação ao que emergia dessas interações.

Ponte (1992, p. 1) contribui para a discussão a esse respeito ao destacar que "as concepções formam-se num processo simultaneamente individual (como resultado da elaboração sobre a nossa experiência) e social (como resultado do confronto das nossas elaborações com as dos outros)". Segundo este autor, mudanças significativas nas concepções só acontecem na presença de abalos muito fortes, advindos de vivências pessoais intensas como, por exemplo, "a participação num programa de formação altamente motivador ou numa experiência com uma forte dinâmica de grupo" (PONTE, 1992, p. 27). Nessa perspectiva, a história revela como o professor Vicente foi transformando suas concepções educacionais ao longo do tempo em que atuou no CECIRS, considerando as suas características individuais, que o constituem como profissional, mas principalmente as influências de seus colegas de trabalho e de outros professores. Durante a entrevista, o professor Vicente ressaltou que, embora não houvesse uma interação direta dele com os demais centros de ciências naquela época, ele ficou conhecendo pessoas de outros lugares nos simpósios, e essas interações também foram muito significativas para o seu trabalho, bem como para o desenvolvimento das suas concepções.

Em um dado momento da entrevista, o professor Vicente recordou a importante contribuição de Milton Zaro, na época, professor-adjunto na UFRGS, para o seu trabalho no CECIRS: 
E na verdade o meu trabalho se deve em grande parte ao Milton Zaro. Ele não era do CECIRS, mas chegou lá, logo no início quando eu fui para lá, com um polígrafo de atividades experimentais, que ele chamou de Matemática Instrumental Experimental, e me convidou a redigir algumas outras atividades. Praticamente, ele tinha um texto bem-elaborado, pronto, e eu acrescentei. Revisamos juntos aquele texto, e saiu o livro publicado pela Fundação de Recursos Humanos. (Dados de entrevista realizada para esta pesquisa)

Esse livro de autoria do professor Milton Zaro em parceria com Vicente Hillebrand, denominado Matemática Experimental, articula "treinar o professor na redação de textos e experimentos, desenvolver a criatividade do professor no desenvolvimento de suas atividades com os alunos e aplicar o método científico na matemática, através da técnica da redescoberta" (HILLEBRAND; ZARO, 1999, p. 8), num processo cujo objetivo se mostra coerente às ações propostas pelo CECIRS: a renovação do ensino, em especial, neste caso, o ensino de matemática. Numa perspectiva crítica, os autores iniciam o texto fazendo uma breve reflexão acerca do ensino e da aprendizagem da matemática, em termos de $1^{\circ}$ grau (Ensino Fundamental), e reconhecem a problemática que gira em torno do perfil do aluno atual, cujo estereótipo é marcado pela pouca capacidade crítica e criadora (HILLEBRAND; ZARO, 1999, p. 7). Dito de outro modo, essa inquietação decorre da constatação das consequências de um ensino no qual, claramente, o centro do processo é o professor, e não o aluno, ou seja, as ações de pensar, criar e criticar do estudante ficam reduzidas e, portanto, sua capacidade de aprendizagem, prejudicada. Nesse sentido, os autores alertam para o fato de que, "normalmente, os professores apresentam aos alunos o conhecimento acabado, pronto, não dando oportunidade para estabelecer relações e descobrir propriedades e muito menos comunicar ideias (conclusões) com clareza e objetividade" (HILLEBRAND; ZARO, 1999, p. 8). É por essa razão que muitos alunos não criam o hábito de pensar e acabam encontrando grandes dificuldades quando se deparam com situações em que o professor não lhes responde imediatamente a todas as perguntas (HILLEBRAND; ZARO, 1999, p. 7), ou seja, quando precisam deixar de ser sujeitos passivos, simples receptores de informações, para se tornar sujeitos participativos no processo de ensino e aprendizagem.

Nas primeiras páginas do livro, Hillebrand e Zaro (1999) acrescentam que é fundamental que o professor busque desenvolver a sua criatividade, relacionando a matemática com outras ciências, lembrando-se de que "o ensino de matemática não deve ser um fim, mas um meio através do qual o aluno é levado a adquirir um estágio de compreensão, consciência e raciocínio" (HILLEBRAND; ZARO, 1999, p. 2). Para isso, sugerem que o professor procure "quebrar" a rotina da sala de aula, levando o aluno para conhecer o mundo que o cerca, dando a ele condições de se apropriar dos conhecimentos matemáticos e relacioná-los com os acontecimentos do seu dia a dia (HILLEBRAND; ZARO, 1999, p. 9).

É possível observar que uma das finalidades dos autores é fazer com que os professores reconheçam que a sua responsabilidade como educadores vai além de simplesmente transferir o conhecimento, mas que o importante é buscar pro- 
porcionar situações de aprendizagem ao aluno "na descoberta daquilo que deve ser conhecido. Desta forma o professor não estará privando o estudante do prazer da descoberta, ao mesmo tempo em que estará sendo verdadeiramente útil, na medida em que 'faz' pensar" (HILLEBRAND; ZARO, 1999, p. 7).

Durante a entrevista, o professor Vicente comentou a respeito das atividades contidas no livro:

Com aquelas atividades experimentais, fazia-se uma matemática que o Plínio [colega no CECIRS] chamava de indutiva (método indutivo); fazer medições, relacionar aquelas medidas e chegar a uma conclusão; descobrir coisas e tentar generalizar descobertas matemáticas, como, por exemplo, a relação de Pitágoras, entre outras. (Dados de entrevista realizada para esta pesquisa)

Em cada uma das atividades, são apresentados, inicialmente, o objetivo, em seguida, os fundamentos teóricos, para facilitar a compreensão do experimento, e, por fim, a parte prática, com a relação dos materiais necessários e os procedimentos experimentais. Essa interação, que resultou em uma publicação (HILLEBRAND; ZARO, 1999), demonstra o quão importante foi a contribuição de Milton Zaro para o desenvolvimento das concepções do professor Vicente. Esse reconhecimento foi reafirmado por ele durante a entrevista: "Eu não teria feito nada daquilo se não tivesse tido, como eu disse, o Milton Zaro, que veio já com esses experimentos. Já tinha uma proposta" (Dados de entrevista realizada para esta pesquisa).

Nota-se que o estabelecimento de outras relações constitui, sem dúvida, relevante contribuição para a (trans)formação das concepções do professor Vicente. Dentre elas, nosso entrevistado destaca: “O Plínio, o Roque tiveram muita influência no meu trabalho [...]. As contribuições e influências deles foram muito preciosas. O Roque questionava muito, e nos motivava a ler [...]. O Plínio também me incentivava muito, a fazer, a redigir coisas" (Dados de entrevista realizada para esta pesquisa). Roque Moraes, assim como Plínio Fasolo, foi importante personagem na história do Centro de Ciências do Rio Grande do Sul. Durante a entrevista, o professor Vicente demonstrou a grande satisfação que sentia por ter dividido a mesma sala com ambos, assim como pela oportunidade de ter compartilhado suas experiências e suas ideias com pessoas ricas em saberes, que muito acrescentaram à sua formação. Nesse sentido, ele assumiu:

As nossas conversas diárias eram sobre educação, sobre enfoque, sobre maneiras de abordar um conteúdo. Isso era riquíssimo, nós tínhamos o dia inteiro para crescer. O Plínio, depois o Roque, sentaram anos do meu lado. E a gente falava, discutia, o Plínio era muito instigador também. [...] Dava uma aula, tínhamos aula particular um com o outro, muito, muito maravilhoso. (Dados de entrevista realizada para esta pesquisa). 
É ainda relevante mencionar o valor das leituras feitas pelo professor Vicente no tempo em que esteve no CECIRS. Na entrevista, ele citou duas obras que contribuíram para mobilizar uma reflexão sobre a sua própria prática. A primeira leitura oportunizada a ele foi o livro A Criança e o Número, de Constance Cami; e a segunda, Ensinar a Pensar, de Raths; ambas, indicadas pelo professor Roque Moraes. A respeito disso, o professor Vicente afirmou:

Isso tudo ajudou. Então fui lendo e vendo que há maneiras diferentes de trabalhar. Pensar sobre a maneira de fazer diferente... a matemática... muito abstrata, torná-la concreta. Isto foi me oportunizado lá. E curso após curso eu fui ampliando e modificando meu modo de ver e fazer meu trabalho. (Dados de entrevista realizada para esta pesquisa)

Diante dessas considerações, pode-se distinguir que a mudança ocorreu em direção a uma pedagogia que visa a um ensino embasado na realidade concreta do aluno, aspecto próprio tanto da pedagogia libertadora como da pedagogia crítico-social dos conteúdos. Em síntese, para a primeira, “aprender é um ato de conhecimento da realidade concreta, isto é, da situação real vivida pelo educando, e só tem sentido se resulta de uma aproximação crítica dessa realidade" (LIBÂNEO, 2001, p. 35); para a segunda, o papel da escola consiste primordialmente na difusão de conteúdos, entretanto, "não [de] conteúdos abstratos, mas vivos, concretos e, portanto, indissociáveis das realidades sociais" (LIBÂNEO, 2001, p. 38). Ambas, coerentes entre si nessa exterioridade, contrapõem-se à pedagogia tradicional, considerando-se que esta tem em vista unicamente depositar informações no aluno, e também à pedagogia renovada, que visaria a uma renovação psicológica individual (LIBÂNEO, 2001, p. 33). Por fim, o professor Vicente conclui:

Eu aprendi muito, modifiquei pontos de vista. Eu entrei de um jeito e fui evoluindo na minha maneira de ver a educação, de ver o ensino da matemática, de ver a abordagem da matemática. Eu nunca tinha tido antes uma orientação diferente de como dar aula. (Dados de entrevista realizada para esta pesquisa)

Outra presença bastante marcante na trajetória do professor Vicente no CECIRS foi a de Paulo Freire, pedagogo renomado não só no Brasil, mas também no mundo inteiro, que contribuiu de forma expressiva, principalmente no que diz respeito à educação popular. Ao comentar sobre a intensidade dessa interação, o professor Vicente mostrou-se muito satisfeito com os resultados. Destacou: "Tive o privilégio de participar de um encontro com Paulo Freire em Pelotas; até foto com ele tenho e também um livro autografado (Extensão ou Comunicação). Penso que Paulo Freire influenciou a todos nós do CECIRS" (Dados de entrevista realizada para esta pesquisa).

Por meio de sua teoria pedagógica, a pedagogia libertadora ou problematizadora, Paulo Freire é um autor que ultrapassou as fronteiras do Brasil, tornando-se mundialmente reconhecido. Foi preso em 1964 por deliberação do Golpe 
Militar e exilado no Chile, onde viveu durante 14 anos. Logo, em 1965, escreveu seu primeiro livro, intitulado Educação como prática de liberdade. Um pouco mais tarde, em 1970, publicou Pedagogia do Oprimido, uma de suas obras mais conhecidas. Assim como estas, diversas outras publicações de Paulo Freire apresentam ideias que se tornaram foco de discussões ao longo dos anos, expressando um grande valor, uma vez que servem de base para a formação e/ou a transformação das concepções educacionais, tendo seus pressupostos adotados por muitos professores no modo como desenvolvem sua docência.

Ao longo da entrevista, o professor Vicente reconheceu a importância não somente do contato que teve pessoalmente com Paulo Freire durante o encontro realizado em Pelotas, mas também o valor presente nas leituras de seus livros. A esse respeito, ele enfatizou:

Todos nós lemos várias obras dele, uns mais outros menos, mas todos nós lemos e acredito que nos impregnamos com suas ideias. Havia diversos livros dele na biblioteca do CECIRS. Suas ideias contribuíram para repensar minhas concepções de educação e com isso contribuíram para modificar minha prática pedagógica. (Dados de entrevista realizada para esta pesquisa)

Além dessas interações, o professor Vicente mencionou ainda a relevante contribuição, mesmo que indireta, do professor Ubiratan d'Ambrosio, da Unicamp. Na entrevista, ele fez referência a um conjunto de materiais disponível no CECIRS naquela época que havia sido elaborado por um grupo de professores do qual um dos coordenadores era o professor Ubiratan e que abordava os conteúdos de geometria experimental, funções e equações e inequações. Acerca disso, nosso entrevistado acrescentou:

Havia rico material de matemática sobre funções, geometria, equações e inequações e estatística. Eu peguei aquele material e comecei a estudá-lo. Era um azul sobre equações e inequações, um verde sobre funções, um vermelho sobre geometria. Riquíssimo. Isso foi elaborado por equipes magníficas da Unicamp. O famoso Ubiratan de Ambrosio foi um dos coordenadores do projeto. (Dados de entrevista realizada para esta pesquisa)

Para que seja possível melhor compreender a influência desse material, sobretudo das ideias do professor Ubiratan no desenvolvimento das concepções do professor Vicente, é necessário recapitular a história e fazer inicialmente uma reflexão envolvendo aspectos importantes do desenvolvimento desses textos.

O projeto de desenvolvimento curricular denominado "Novos Materiais para o Ensino de Matemática”, que deu origem aos referidos livros, iniciou-se no ano de 1973, através de um convênio entre MEC e Unicamp, estando, na época, entre um dos mais avançados do mundo. Para a versão final deste projeto, foram produzidos três materiais. São eles: Geometria Experimental, Função e Equações e Inequações, com capas nas cores vermelho, verde e azul, respectivamente. É importante ressaltar que cada um desses materiais era composto por Livro do Aluno, 
Livro do Professor e um kit com materiais experimentais (STAVIS, 2011). Contudo, o essencial a ser identificado nesse contexto são os pressupostos de aprendizagem que possam ter influenciado o professor Vicente ao longo da sua trajetória no Centro de Ciências do Rio Grande do Sul. Para tanto, cabe questionar: qual enfoque foi dado ao ensino da matemática na publicação desses materiais?

Stavis (2011) defende, na sua dissertação de mestrado, que "as ideias do professor Ubiratan foram fundamentais para imprimir a esse material uma nova concepção de ensino de matemática” (STAVIS, 2011, p. 90). Segundo ela, conforme depoimento dado pelo professor Ubiratan para a sua pesquisa, a fonte de tais ideias esteve na "matemática realista", criação do matemático holandês Hans Freudenthal, que define a matemática como sendo uma atividade humana constituída por: organizar, relacionar, generalizar, provar e formalizar o mundo a nossa volta a partir da redescoberta. Nas ideias de Freudenthal (1973, apud STAVIS, 2011, p. 18), destaca-se o valor de atividades que partam de problemas da vida real e que estejam ancoradas em ações concretas, entre elas: recortar, desenhar, colar, medir e pavimentar (STAVIS, 2011, p. 18). O estudo de Stavis (2011) revela, por meio da justificativa do projeto (Convênio Premen/Unicamp), que as concepções do professor Ubiratan iam em direção a um ensino voltado para toda a população, com ênfase, principalmente, no desenvolvimento da capacidade de pensar do aluno e na utilização dos conhecimentos matemáticos na vida prática.

Entende-se que as ideias do professor Ubiratan para o ensino de matemática naquela época tiveram influência direta na elaboração dos materiais, que, posteriormente, foram utilizados pelo professor Vicente como base para os seus cursos no CECIRS. Dessa forma, acredita-se que essas percepções possam ter contribuído, mesmo que indiretamente, para "trans-formar" as concepções do professor Vicente. Stavis (2011) reescreve a caracterização do material, contida na primeira página do Livro do Professor:

Cada atividade coloca o aluno em interação com objetos concretos, orientando-o, gradativamente, para as análises lógicas. Procurou-se, também, tornar a aprendizagem mais objetiva e natural, facilitando-se assim a formação de um ambiente em que o aluno sinta que pode experimentar, pode cometer erros, pensar por si mesmo, escolher métodos para solucionar uma situação-problema e, sobretudo, pode contar, quando necessário, com a orientação de uma pessoa mais experiente, o professor. As atividades começam com uma questão desafiadora, onde o conceito a ser trabalhado está inerente. Após a colocação da situação-problema, os alunos devem fazer a sua análise crítica, procurando prever possíveis soluções, que serão, posteriormente, confrontadas com os resultados obtidos durante a realização das experiências. O texto procura orientar atividades, de modo a não ser demasiadamente diretivo, evitando apresentar conclusões a que o aluno possa chegar por seus próprios meios, não limitando sua criatividade, além de procurar ser suficientemente flexível, para atender às tendências de cada aluno. Durante a realização das experiências, o professor só deverá intervir quando solicitado. Poderá também, quando sentir necessidade, seguir este ou aquele caminho. Deverá, ainda, orientar os alunos para que idealizem e executem novas experiências relativas aos assuntos abordados. (STAVIS, 2011, p. 78) 
$\mathrm{Na}$ entrevista, o professor Vicente acrescentou, ainda, que esses livros eram significativos porque apresentavam a matemática de uma forma mais prática, exploratória, e enfatizou: "Não só os textos eram excelentes, mas também o material concreto: cubinhos, balanças, esquadros de madeira, paquímetro de madeira que acompanhavam aquelas publicações. Isso em grande parte foi distribuído para as escolas naquela época" (Dados de entrevista realizada para esta pesquisa). Ele reconheceu e apreciava, também, o grande valor que esse material tinha nos cursos que ministrava no CECIRS e em algumas cidades do interior do Estado. A esse respeito, ele argumentou:

Era um material riquíssimo, que eu comecei a estudar e dar curso sobre eles, sobre estes materiais lá no CECIRS e nos cursos no interior. Então os cursos de semana inteira eu organizava para abordar aqueles três cadernos, ou parte deles. Fazia-se atividade com base nestes materiais. [...] Então isto foi uma grande coisa que apoiou o meu trabalho. (Dados de entrevista realizada para esta pesquisa)

Com base na expressiva contribuição dessas interações, pode-se dizer que o professor Vicente e os demais professores que integravam o Centro de Ciências do Rio Grande do Sul foram privilegiados com um desenvolvimento diferenciado, pois puderam interferir e colaborar para modificar concepções de seus colegas, à medida que atuavam, por meio de um esforço coletivo e contínuo, na construção de conhecimentos sobre a realidade educacional. Nesse contexto, Borges et al. (2012, p. 217) sublinha a importante contribuição da "forma de trabalhar e decidir em conjunto" presente na atuação do grupo do CECIRS, sempre "buscando consensos construídos no debate, com respeito às divergências [...]”.

Durante a entrevista, o professor Vicente demonstrou sua satisfação em ter dividido o espaço e o tempo do CECIRS com pessoas que agregaram muito às suas concepções sobre o ensinar e o aprender. Essa afirmação fica evidente quando ele enfatiza:

Estávamos rodeados o dia inteiro com Roque, Plínio, Henig, Regina, Adria, Ellen, Valderez! E esta interação toda contribuiu, totalmente! Nós éramos envolvidos com uma aura diária diferente de uma escola. [...] Não é desprezar, nem menosprezar escolas, mas na escola não se oportuniza essa troca de vivências, esse compartilhar de experiências. Cada um corre para a sua aula, cada um por si. E nós no CECIRS compartilhávamos, discutíamos ideias. Havia contestações, mas esta contestação fazia pensar, mudar de ideia. Isto é um crescimento extraordinário. (Dados de entrevista realizada para esta pesquisa)

Essa afinidade, na visão do grupo, em termos do que se esperava alcançar para a educação, resultou na organização de um material próprio do CECIRS, cujo objetivo era, dentre outros, compartilhar com os demais professores artigos e roteiros de estudo, incluindo atividades para a utilização em sala de aula com alunos. O CECIRS tinha publicações próprias desde o início, veiculadas em boletins destinados a professores de ciências. A finalidade principal desse material era divulgar 
as ideias sobre educação científica compartilhadas nos centros, com ênfase nas técnicas de ensino, e informar sobre atividades e oportunidades oferecidas pelo centro para um ensino considerado como melhor (BORGES, 1997). Ao longo dos anos, essa ação do centro foi se alterando, e o material, que antes era formado apenas por publicações dos membros do CECIRS, passou a contar com a colaboração dos demais professores que participavam dos cursos e também dos alunos participantes do Programa Estadual de Feiras de Ciências, objetivando incentivar a produção própria (CECIRS, 1999, p. 36). Inicialmente, o material foi intitulado Informativo PROCIRS, depois, passou a ser chamado de Boletim técnico do PROCIRS e, por fim, de Revista do PROCIRS.

Foi possível observar na entrevista que, para o professor Vicente, essa ação do centro foi bastante significativa, pois, à medida que os textos iam sendo escritos, os demais colegas liam e se comprometiam com um exame crítico dessas produções, gerando discussões positivas e possibilitando um intercâmbio de ideias. Nesse sentido, o professor Vicente destacou: “Todos os artigos eram escritos por nós. E o que eu escrevia, várias pessoas liam e faziam suas críticas. Isto é um crescimento extraordinário. E, olha, sem modéstia, o grupo era excelente, o grupo era de altíssimo nível, incomparável" (Dados de entrevista realizada para esta pesquisa). E concluiu dizendo:

O que eu aprendi com os meus colegas no CECIRS é impagável e por isso serei eternamente grato aos meus amigos Plínio Fasolo e Ronaldo Mancuso, por terem me convidado a integrar esse grupo fabuloso. Muito, muito mesmo do que sou hoje como professor devo à minha vivência no CECIRS. (Dados de entrevista realizada para esta pesquisa)

\section{CONSIDERACְ̃̃ES FINAIS}

Ao longo desta investigação histórica, foi possível tecer algumas considerações. Destaca-se a influência do CECIRS no processo de educação continuada de professores de ciências e matemática, representando um espaço privilegiado de discussão e troca de experiências, envolvendo questões importantes daquele período no âmbito da educação.

Constatou-se que, assim como as demais disciplinas científicas, o ensino da matemática no fim dos anos de 1950 era marcado por um quadro geral considerado desfavorável diante das metas pretendidas para o ensino secundário (Ensino Médio) brasileiro. A concepção tradicional de ensino preponderava, as aulas eram essencialmente expositivas, com ênfase em cálculos extensos, demonstrações e memorização de conceitos. Esse quadro, naturalmente, influenciou os primeiros trabalhos do CECIRS, considerando-se que a sua criação, em 1965, assim como a criação dos demais centros de ciências, aconteceu tendo em vista mudanças estratégicas nos currículos escolares, capazes de contribuir para um perfil de cidadão cada vez mais sintonizado com o desenvolvimento científico, tecnológico e industrial. 
Foi possível reconhecer, ainda, mudanças significativas nas ações do CECIRS no início da década de 1980, quando a estratégia adotada pelo centro transformou-se em um trabalho conjunto com as Delegacias de Educação estaduais (DE-RS) e com os professores em exercício, deixando de ser uma tarefa exclusiva dos especialistas e mostrando um enfraquecimento da influência tecnicista sobre as ações do CECIRS. Esse foi um marco importante para o desenvolvimento desta pesquisa, pois foi nesse período que o professor Vicente Hillebrand passou a integrar a equipe do centro, assumindo os trabalhos referentes à matemática. Isso significa, portanto, que as concepções assumidas pelo CECIRS e toda a historicidade a partir desse período tiveram valor significativo para a compreensão do presente trabalho.

Embora não excluindo a influência da pedagogia tecnicista sobre as ações do grupo do CECIRS, a partir dos anos de 1980, passaram a predominar alguns aspectos que caracterizam a pedagogia libertadora de Paulo Freire. Dentre esses aspectos, destacam-se a importância de contextualizar os conteúdos de sala de aula e a necessidade de o professor criar as pontes entre o conhecimento acumulado pela humanidade e o futuro.

A investigação realizada por meio de uma entrevista semiestruturada possibilitou a compreensão de aspectos relacionados ao trabalho desenvolvido pelo professor Vicente Hillebrand nos inúmeros cursos realizados na sede do PROCIRS/CECIRS e em diversas cidades do interior do Estado. Ficou evidente não apenas a importância que o trabalho com grupos de estudo teve na história de vida profissional do professor Vicente Hillebrand, mas também seu valor de contribuição na atuação pedagógica dos professores que participavam desses grupos, o que se refletia diretamente na qualidade do ensino nas escolas. O reconhecimento dessa valiosa contribuição dos grupos de estudo pode ser naturalmente notado em muitas avaliações dos cursos feitas pelos próprios professores participantes, pois eles se mostravam entusiasmados com as novas possibilidades metodológicas que os cursos lhes oportunizavam. Ficou evidente que a abordagem associada à prática desses professores era predominantemente a abordagem tradicional de ensino. Assim, a mudança em termos teóricos e metodológicos pretendida nos cursos ministrados pelo professor Vicente ia em direção a despertar no aluno a criatividade, a experimentação, o questionamento, partindo de atividades concretas. Além disso, pretendia-se desenvolver na criança a independência, a confiança, a ordem e a coordenação, de forma que o aluno descobrisse relações matemáticas a partir de sua prática, com base na técnica da redescoberta. É possível afirmar, portanto, que essa mudança na prática dos professores almejava uma postura coerente com os princípios da pedagogia escolanovista e da pedagogia libertadora de Paulo Freire. De maneira geral, os professores assumiam a necessidade de aprimorar seus conhecimentos pedagógicos, tinham consciência da importância de buscar uma formação continuada.

Em meio a esse compartilhamento de experiências, alguns personagens desta história se destacaram no desenvolvimento das concepções do professor Vicente e, de alguma forma, também foram influenciados por suas ideias. Destaca-se a participação 
de Milton Zaro ao propor o desenvolvimento de um livro em parceria com o professor Vicente, cujos objetivos consistiam em treinar o professor na redação de textos e em experimentos e desenvolver a sua criatividade tendo em vista a aplicação do método científico na matemática, por meio da técnica da redescoberta. Os autores sugerem que o professor procure "quebrar" a rotina da sala de aula, levando o aluno para conhecer o mundo que o cerca, dando a ele condições de se apropriar dos conhecimentos matemáticos e de relacioná-los com os acontecimentos do seu dia a dia. Encontram-se mais fortemente nessa interação aspectos próprios tanto da pedagogia crítico-social dos conteúdos como da pedagogia libertadora. A predominância desta última pode ser atribuída, dentre outras coisas, ao fato de o professor Vicente ter tido a oportunidade de participar de um encontro com o inspirador e mentor da pedagogia libertadora, Paulo Freire.

Constatou-se ainda a influência, mesmo que indireta, do professor Ubiratan d'Ambrosio, da Unicamp, através de um conjunto de materiais disponível no CECIRS de sua autoria naquela época, que iam em direção a um ensino com ênfase no desenvolvimento da capacidade de pensar do aluno e na utilização dos conhecimentos matemáticos na vida prática. Verificou-se, ainda, o valor de atividades que partissem de problemas da vida real, ancoradas em ações concretas, entre elas: recortar, desenhar, colar, medir e pavimentar. Dessa forma, identificam-se, mais uma vez, aspectos relacionados às pedagogias crítico-social dos conteúdos e libertadora.

Em um sentido mais amplo, o professor Vicente Hillebrand deixou transparecer que todas as interações foram muito significativas, pois proporcionaram um desenvolvimento diferenciado, uma vez que, no CECIRS, todos podiam interferir e colaborar para modificar as concepções de seus colegas por meio de um esforço coletivo e contínuo.

A análise permitiu identificar muitas ideias defendidas pelo professor Vicente Hillebrand para a educação matemática, válidas também para a educação em ciências. Desse modo, este estudo da historicidade, com a contextualização das teorias educacionais em diferentes períodos, pode auxiliar na compreensão do que temos no momento presente. Propicia que nós, professores, repensemos as nossas ideias com relação à nossa prática pedagógica e, de forma geral, aos aspectos direcionados à forma como se faz educação na atualidade.

\section{NOTAS}

${ }^{1}$ Vicente Hillebrand possui Licenciatura em Ciências (1974) e em Física (1996) pela Pontifícia Universidade Católica do Rio Grande do Sul (PUCRS), Mestrado em Educação pela PUCRS (1996) e Doutorado em Educação pela PUCRS (2000). Atualmente é professor titular da Faculdade de Física da PUCRS. Atuou principalmente nos seguintes temas: ensino de matemática e de ciências, educação matemática, metodologia de ensino de matemática e formação continuada de professores. 


\section{REFERÊNCIAS}

BOGDAN, R.; BIKLEN, S. Investigação qualitativa em educação. Portugal: Porto, 1994.

BORGES, R. M. R. Transição entre paradigmas: concepções e vivências no CECIRS (Centro de Ciências do Rio Grande do Sul). 1997. 346 f. Tese (Doutorado em Educação) - Faculdade de Educação, Pontifícia Universidade Católica do Rio Grande do Sul, Porto Alegre, 1997.

BORGES, R. M. R; SILVA, A. F. D.; DIAS, A. L. M. Ciência, História, Educação e Cultura: dos Centros de treinamento de professores de Ciências aos atuais Centros e Museus interativos. (Projeto de Pesquisa) Programa Pró-Cultura (CAPES/ MinC), Porto Alegre, 2009.

BORGES, R. M. R. et al. A História do Centro de Ciências do Rio Grande do Sul (CECIRS). In: BORGES, R. M. R.; IMHOFF, A. L.; BARCELLOS, G. B. (Org.). Educação e Cultura Cientifica e Tecnológica - centros e museus de ciências no Brasil. Porto Alegre: EDIPUCRS, p. 211-222, 2012.

CECIRS. Centro de Treinamento para Professores de Ciências do Rio Grande do Sul. Proposta de ações do CECIRS para o periodo de 1999 a 2002. Porto Alegre, 1999.

FREIRE, P. Pedagogia do Oprimido. São Paulo: Paz e Terra, 1994.

GADOTTI, M. História das idéias pedagógicas. 7. ed. São Paulo: Ática, 1999. 319 p.

HILLEBRAND, V. Matemática Instrumental e Experimental. Boletim Técnico do PROCIRS, Porto Alegre, v. 1, n. 1, p. 14, mar./abr. 1985a.

. Relação entre Unidades de Comprimento. Boletim Técnico do PROCIRS, Porto Alegre, v. 1, n. 2, p. 6-7, mai./jun. 1985 b.

. Autonomia Intelectual. Boletim Técnico do PROCIRS, Porto Alegre, v. 1, n. 2, p. 19, mai./jun. 1985c.

. Estudo de Frações. Boletim Técnico do PROCIRS, Porto Alegre, v. 1, n. 3, p. 4-6, jul./set. 1985d.

. Fazer pensar versus aplicar fórmulas. Boletim Técnico do PROCIRS, Porto Alegre, v. 1, n. 4, p. 18, out./dez. 1985e.

. Matemática no $1^{\circ}$ grau - Realidade e Perspectivas (Mudanças Metodológicas e Função do Professor). Boletim Técnico do PROCIRS, Porto Alegre, v. 2, n. 7, p. 17, jul./set. 1986. 1988.

. Redescobertas em trigonometria. Revista do PROCIRS, Porto Alegre, v.1, n. 1, p. 33, jan./jun.

. Contribuição de um Grupo de Estudo na atuação pedagógica de professores de Matemática. 1996. $184 \mathrm{f}$. Dissertação (Mestrado em Educação) - Faculdade de Educação, Pontifícia Universidade Católica do Rio Grande do Sul, Porto Alegre, 1996.

. Reflexões sobre a ação pedagógica. Ciência \& Educação, Porto Alegre, v. 1, n. 1, p. 4, jan./jun. 1998.

- A percepsão da Matemática por professoras das séries iniciais e sua repercussão na prática pedagógica. 2000.

464 f. Tese (Doutorado em Educação) - Faculdade de Educação, Pontifícia Universidade Católica

do Rio Grande do Sul, Porto Alegre, 2000.

. Avaliações de cursos de Matemática. FDRH, Porto Alegre, 2011.

HILEBRAND, V.; ZARO, M. Matemática Experimental. 3. Ed. São Paulo: Ática, 1999. 119 p.

LIBÂNEO, J. C. Democratização da escola pública: a pedagogia crítico-social dos conteúdos. 17. ed. São Paulo: Loyola, 2001.

LÜDKE, M.; ANDRÉ, M. Pesquisa em educação: abordagens qualitativas. São Paulo: E.P.U., 2001.

MORAES, R.; GALIAZZI, M. C. Análise Textual Discursiva. Ijuí: UNIJUI, 2011.

PONTE, J. P. Concepções dos Professores de Matemática e Processos de Formação. In: Educação matemática: Temas de investigação. Lisboa: Instituto de Inovação Educacional, 1992, p. 239.

SAVIANI, D. As concepscões pedagógicas na bistória da educação brasileira. Campinas [s.n.], 2005.

. História das Ideias Pedagógicas no Brasil. 2. ed. rev. ampl. Campinas: Autores Associados, 2008.

SILVA, S. A. da; ARAUJO, J. A. A. Maria Montessori e a criação do Material Dourado como instrumento metodológico para o Ensino de Matemática nos anos iniciais da escolarização. Disponível em: < http:/ /www.uems.br/ eventos/semana/arquivos/31_2011-09-05_14-28-02.pdf>. Acesso em: 10 set. 2012. 
STAVIS, J. C. O contexto de produção e tendências teórico-metodológicas de um material que marcon o ensino de Matemática: Geometria experimental. 2011. 126 f. Dissertação (Mestrado em Educação) - Universidade São Francisco, Itatiba, 2011

TEIXEIRA, E. B. A análise de dados na pesquisa científica: importância e desafios em estudos organizacionais. Desenvolvimento em Questão. v. 1, n. 2, p. 177-201, jul./dez. 2003.

VIÊRA, M. M. O entrelaçar de histórias: o Centro de Ciências do Rio Grande do Sul (CECIRS) e a vida de um professor de ciências. 2011. 145 f. Dissertação (Mestrado em Educação em Ciências e Matemática) - Pontifícia Universidade Católica do Rio Grande do Sul/PUCRS, Porto Alegre/RS, 2011.

YIN, R. K. Estudo de caso: planejamento e métodos. 4. ed. Porto Alegre: Bookman, 2010.

Data de recebimento: 07/09/2014

Data de Aprovação: 14/01/2015

Data da Versão final: 13/02/2015

\section{Contato:}

Glauce Agnes Balestrin

Avenida Ipiranga, 6681 - Partenon, Porto Alegre - RS, Brasil - 90619-900

Email: gb.balestrin@gmail.com 